T.F. is a consultant for LivaNova. G.S. is a consultant for Sorin Group Italia (LivaNova subsidiary).

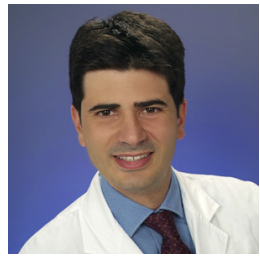

\section{RAPID-DEPLOYMENT AORTIC VALVE SYSTEMS: THE SURGEONS' ALTERNATIVE TO TRANSCATHETER AORTIC VALVE IMPLANTATION?}

\section{To the Editor:}

The search for innovative solutions to achieve better outcomes for patients with aortic stenosis still continues in the setting of aortic valve replacement performed under cardiopulmonary bypass and aortic crossclamping (XCL). In their report on the TRANSFORM (Multicenter Experience With Rapid Deployment Edwards INTUITY Valve System for Aortic Valve Replacement) trial, Barnhart and colleagues ${ }^{1}$ noted that the trial evaluated the performance of the INTUITY rapid-deployment system (Edwards Lifesciences Corporation, Irvine, Calif) out to 1-year follow-up. Barnhart and colleagues ${ }^{1}$ emphasized the importance of the meaningful reductions in cardiopulmonary bypass and XCL obtained with the INTUITY valve, although no control group was available for comparison of clinical outcomes (cerebral microembolism, paravalvular leak, etc). Surgical times, however, were reported to compare favorably with those of the Society of Thoracic Surgeons database; in other words, trained surgeons with expertise in the INTUITY valve system were compared with the rest of the US surgeons, including residents. Moreover, as a further indirect comparison term, implantation times (XCL time of 49 minutes for full sternotomy) were more than double those with the Perceval sutureless aortic valve (LivaNova PLC, London, United Kingdom), which had an XCL time of 18 minutes. $^{2}$

It would have been interesting to have information on the explantation technique; it could be challenging. At our institution, explantation of the INTUITY valve resulted in a tear at the base of the anterior mitral leaflet in 1 patient. This necessitated transaortic aortomitral

The Editor welcomes submissions for possible publication in the Letters to the Editor section that consist of commentary on an article published in the Journal or other relevant issues. Authors should: • Include no more than 500 words of text, three authors, and five references. • Type with double-spacing. $\bullet$ See http://jtcs.ctsnetjournals.org/ misc/ifora.shtml for detailed submission instructions. • Submit the letter electronically via jtcvs.editorialmanager.com. Letters commenting on an article published in the JTCVS will be considered if they are received within 6 weeks of the time the article was published. Authors of the article being commented on will be given an opportunity of offer a timely response ( 2 weeks) to the letter. Authors of letters will be notified that the letter has been received. Unpublished letters cannot be returned.

junction reconstruction, which was performed successfully through a ministernotomy, with good clinical and echocardiographic outcomes.

High rates of postoperative permanent pacemaker implantation were reported in this trial. ${ }^{1}$ The presence of preoperative right bundle branch block may partially account for this finding, as also reported in a previous study with the Perceval sutureless aortic valve. ${ }^{3}$ Several technical precautions have been implemented in sutureless aortic valve replacement, however, leading to significantly lower rates of postoperative pacemaker implantation. ${ }^{4}$

In our opinion, rapid-deployment aortic valve prostheses have the potential to shorten surgical time. Future research will determine whether this advantage translates into better outcomes for patients at high risk.

T. Fischlein, $M D$

G. Santarpino, $M D$

Department of Cardiac Surgery

Paracelsus Medical University

Nuremberg, Germany

\title{
References
}

1. Barnhart GR, Accola KD, Grossi EA, Woo YJ, Mumtaz MA, Sabik JF, et al; TRANSFORM Trial Investigators. TRANSFORM (Multicenter Experience With Rapid Deployment Edwards INTUITY Valve System for Aortic Valve Replacement) US clinical trial: performance of a rapid deployment aortic valve. J Thorac Cardiovasc Surg. 2017;153:241-51.e2.

2. Flameng W, Herregods MC, Hermans H, Van der Mieren G, Vercalsteren M, Poortmans G, et al. Effect of sutureless implantation of the Perceval S aortic valve bioprosthesis on intraoperative and early postoperative outcomes. J Thorac Cardiovasc Surg. 2011;142:1453-7.

3. Vogt F, Pfeiffer S, Dell'Aquila AM, Fischlein T, Santarpino G. Sutureless aortic valve replacement with Perceval bioprosthesis: are there predicting factors for postoperative pacemaker implantation? Interact Cardiovasc Thorac Surg. 2016; 22:253-8.

4. Fischlein T, Gersak B, Pfeiffer S. How to prevent a pacemaker implantation after sutureless bioprosthesis. J Thorac Cardiovasc Surg. 2016;152:635-6.

http://dx.doi.org/10.1016/j.jtcvs.2017.03.087

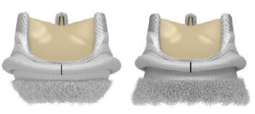

\section{RAPID DEPLOYMENT AORTIC VALVE SYSTEMS:} THE

\section{SURGEONS' ALTERNATIVE TO TRANSCATHETER AORTIC VALVE IMPLANTATION? \\ Reply to the Editor:}

The authors appreciate the comments and the opportunity to respond. Like other rapid-deployment aortic valve replacement premarket studies, TRANSFORM (Multicenter Experience With Rapid Deployment Edwards INTUITY Valve System for Aortic Valve Replacement) ${ }^{1}$ was a single-armed, observational study approved by the Food and Drug Administration. As we noted in our manuscript, the randomized trial by Borger and colleagues ${ }^{2}$ 